\title{
Dificuldades de pacientes e cuidadores na realização do cateterismo intermitente limpo: revisão de escopo
}

\author{
Difficulties of patients and caregivers in performing clean intermittent \\ catheterization: scoping review
}

\author{
Dificultades de los pacientes y cuidadores en la realización del cateterismo \\ intermitente limpio: revisión de alcance
}

Leonardo Orlandin",*, Aguinaldo Nardi², Raphael Raniere de Oliveira Costa ${ }^{3}$, Alessandra Mazzo $^{2}$

ORCID IDS

Orlandin L (D) https://orcid.org/0000-0002-3449-9837

Mazzo A (D) https://orcid.org/0000-0001-5074-8939

Nardi A (D) http://orcid.org/0000-0002-3095-5567

Costa RRO (D) https://orcid.org/0000-0002-2550-4155

\section{COMO CITAR}

Orlandin L; Mazzo A; Nardi A; Costa RRO. Dificuldades de pacientes e cuidadores na realização do cateterismo intermitente limpo: revisão de escopo. ESTIMA, Braz. J. Enterostomal Ther., 18: e1520. https:// doi.org/10.30886/estima.v18.907_PT

\begin{abstract}
RESUMO
Objetivo: Identificar as principais dificuldades relatadas pelos pacientes e cuidadores no uso do cateterismo intermitente limpo descritas na literatura científica. Métodos: Revisão de escopo com estudos publicados em português, inglês ou espanhol, sem limite de data, em base de dados eletrônicas e bibliotecas digitais, utilizando descritores e palavras-chave. Resultados: Foram identificados 790 estudos, sendo incluídos 34 estudos publicados entre 1984 e 2019. As principais dificuldades relatadas na realização do cateterismo intermitente limpo foram referentes a inserção do cateter, dor, desconforto, trauma uretral, banheiros públicos com instalações inadequadas, dificuldades físicas e falta de acesso aos insumos necessários. Conclusão: Os estudos analisados evidenciam as dificuldades que os pacientes usuários do cateterismo intermitente limpo e seus cuidadores enfrentam no dia a dia, que estão relacionadas à fatores intrínsecos e extrínsecos, institucionais e governamentais e podem diminuir a satisfação e a aderência aos programas de reabilitação vesical, com impacto na qualidade de vida dos pacientes e seus cuidadores. Portanto destaca-se a necessidade de educação em saúde para o adequado ensino da realização do cateterismo intermitente limpo, enfatizando a importância do papel do enfermeiro nesse processo.
\end{abstract}

DESCRITORES: Cateterismo uretral intermitente; Bexiga urinária neurogênica; Reabilitação; Estomaterapia.

\footnotetext{
1. Universidade de São Paulo - Escola de Enfermagem de Ribeirão Preto - Programa de Pós-Graduação em Enfermagem

Fundamental - Ribeirão Preto (SP), Brasil.

2. Universidade de São Paulo - Faculdade de Odontologia de Bauru - Curso de Medicina - Bauru (SP), Brasil.

3. Universidade Federal do Rio Grande do Norte - Escola Multicampi de Ciências Médicas - Caicó (RN), Brasil.

*Autor correspondente: leonardo.orlandin@usp.br

Recebido: Jun. 19, 2020 | Aceito: Ago. 10, 2020
} 


\section{ABSTRACT}

Objective: To identify the main difficulties reported by patients and caregivers in the use of clean intermittent catheterization described in the scientific literature. Methods: Scoping review with studies published in Portuguese, English or Spanish, without date limit, in electronic databases and digital libraries, using descriptors and keywords. Results: 790 studies were identified, including 34 studies published between 1984 and 2019. The main difficulties reported in performing clean intermittent catheterization were related to catheter insertion, pain, discomfort, urethral trauma, public bathrooms with inadequate facilities, physical difficulties and lack of access to necessary inputs. Conclusion: The studies analyzed show the difficulties that patients who use clean intermittent catheterization and their caregivers face on a daily basis, which are related to intrinsic and extrinsic, institutional and governmental factors and can decrease satisfaction and adherence to rehabilitation programs bladder, with an impact on the quality of life of patients and their caregivers. Therefore, it highlights the need for health education for the proper teaching of performing clean intermittent catheterization, emphasizing the importance of the nurse's role in this process.

DESCRIPTORS: Intermittent urethral catheterization; Urinary bladder; neurogenic; Rehabilitation; Enterostomal therapy.

\section{RESUMEN}

Objetivo: Identificar las principales dificultades reportadas por pacientes y cuidadores en el uso de cateterismo intermitente limpio descrito en la literatura científica. Métodos: Revisión de alcance con estudios publicados en portugués, inglés o español, sin límite de fecha, en base de datos electrónica y bibliotecas digitales, utilizando descriptores y palabras clave. Resultados: Se identificaron 790 estudios, que incluyó 34 estudios publicados entre 1984 y 2019. Las principales dificultades señaladas para realizar cateterismo intermitente limpio se relacionaron con la inserción del catéter, dolor, molestias, traumatismo uretral, baños públicos con instalaciones inadecuadas, dificultades físicas y falta de acceso a los insumos necesarios. Conclusión: Los estudios analizados muestran las dificultades que los pacientes que usan cateterismo intermitente limpio y sus cuidadores enfrentan a diario, que están relacionadas con factores intrínsecos y extrínsecos, institucionales y gubernamentales y pueden disminuir la satisfacción y el cumplimiento de los programas de rehabilitación de la vejiga, con un impacto en la calidad de vida de los pacientes y sus cuidadores. Por lo tanto, se destaca la necesidad de educación sanitaria para la enseñanza adecuada de la realización de cateterismo intermitente limpio, haciendo hincapié en la importancia del papel de la enfermera en este proceso.

DESCRIPTORES: Cateterismo uretral intermitente; Vejiga urinaria neurogénica; Rehabilitación; Estomaterapia.

\section{INTRODUÇÃO}

O cateterismo intermitente limpo (CIL) consiste na inserção periódica de cateter vesical com o objetivo de eliminar seu conteúdo e promover o esvaziamento vesical.É uma das principais intervenções adotadas para as disfunções urinárias que cursam com dificuldade de esvaziamento vesical causadas ou não por patologias neurológicas ${ }^{1-4}$.

O procedimento visa prevenir complicações associadas à estase urinária, como a infecção do trato urinário e lesões do trato urinário superior. O CIL possibilita a proteção do trato urinário e a melhora de eventual incontinência urinária e da qualidade de vida em seus âmbitos sociais de autoestima e autonomia ${ }^{1,3}$. A ocorrência de dificuldades técnicas na realização do procedimento pode contribuir para descontinuidade e menor probabilidade do uso do CIL e, consequentemente, acarretar consequências do não tratamento da bexiga urinária neurogênica ${ }^{5}$.

Por se tratar de um procedimento invasivo, pode ocasionar dor e desconforto, além de oferecer riscos em sua realização. É frequente a ocorrência do trauma uretral relacionado à introdução do cateter não lubrificado, ao tipo de material utilizado e à técnica adotada na realização do procedimento. $\mathrm{O}$ trauma uretral ocorre pelo atrito do cateter mal lubrificado contra a mucosa uretral e se caracteriza por dor e/ou sangramento uretral. Além disso, oferece uma porta de entrada a bactérias responsáveis pelo desenvolvimento de infecções do trato urinário. Quando realizado em longo período, pode resultar em estenose uretral, incontinência urinária, disfunção erétil e infertilidade ${ }^{1,6,7}$.

As características dos materiais utilizados na realização do procedimento podem ter impacto no sucesso ou não da técnica, uma vez que alguns desses cateteres podem oferecer maior facilidade de manuseio e execução e menor dor e desconforto à introdução ${ }^{1,8-11}$. No Brasil, os pacientes têm acesso pelo Sistema Único de Saúde (SUS) ao cateter urinário de polivinila (PVC), um material de baixo custo, flexível e sem lubrificantes12. Seu uso geralmente está associado ao aumento da fricção do cateter contra a mucosa uretral e, consequentemente, risco aumentado de trauma uretral. $\mathrm{O}$ uso de cateteres hidrofílicos pré-lubrificados pode tornar o procedimento mais preciso e seguro ${ }^{2,11,13-15}$. 
Nesse contexto de diversidade de materiais e necessidade de adesão do paciente para efetivar o tratamento e riscos inerentes ao procedimento, é imprescindível que os profissionais tenham domínio da habilidade para que promovam ações educativas. As ações educativas efetivas em saúde só se concretizam quando reconhecem a realidade e as experiências prévias dos indivíduos a que se destinam, determinando potencialidades e suscetibilidades, em um olhar integral, que estabelecem objetivos de ensino-aprendizagem frente às dificuldades encontradas. Assim, é necessário tomar conhecimento das dificuldades encontradas pelos pacientes e/ou seus cuidadores no desenvolvimento da técnica, com objetivo de identificar erros e garantir melhor qualidade de vida aos usuários do $\mathrm{CIL}^{16}$.

Alguns estudos apontam como a maior dificuldade na realização do CIL o não domínio da técnica pelos pacientes e/ou seus cuidadores. O posicionamento do paciente durante o procedimento, a adequada visualização do meato uretral, $o$ conhecimento do método e da anatomia uretral permitem aos pacientes e seus cuidadores a sondagem uretral sem trauma e sem dor, evitando-se manobras que possam lesar a uretra ${ }^{5,17}$. Dessa forma, a sistematização do procedimento é fundamental.

Nesse sentido, este estudo tem como objetivo identificar as principais dificuldades relatadas pelos pacientes e cuidadores no uso do cateterismo intermitente limpo descritas na literatura científica.

\section{MÉTODOS}

Estudo realizado por meio de revisão de escopo, conforme a proposta do Joanna Briggs Institute $(\mathrm{JBI})^{18}$. Para a construção da pergunta da pesquisa, aplicou-se a estratégia PCC que representa uma mnemônica para População, Conceito e Contexto, definido assim: $\mathrm{P}$ = pacientes ou cuidadores, $\mathrm{C}=$ dificuldades e $\mathrm{C}$ = realização do cateterismo intermitente limpo. Para a busca e a seleção dos estudos, foi estabelecida a seguinte questão norteadora: "Quais são as dificuldades de pacientes e/ou cuidadores durante a realização do cateterismo intermitente limpo?"

A busca foi realizada por dois pesquisadores independentes, conforme critérios do JBI18, sem limite de data, nas bases de dados e nas bibliotecas digitais Scientific Electronic Library Online (SciELO) e Biblioteca do Conhecimento
Online (b-on), Literatura Latino-Americana e do Caribe em Ciências da Saúde (LILACS), National Library of Medicine (PubMed), The Cochrane Library, Web of Science, Scopus, Cumulative Index to Nursing and Allied Health Literature (CINAHL) e Academic Search Premier (via plataforma EBSCO).

A literatura cinzenta foi identificada através de buscas realizadas no Banco de Teses CAPES, Biblioteca Digital de Teses e Dissertações USP e Busca Integrada USP ${ }^{18}$. Também foram consideradas as referências citadas nos estudos encontrados para identificar possíveis estudos de interesse adicionais à busca ${ }^{19}$.

Para tanto, foram utilizados descritores, palavras-chave e/ou seus sinônimos, de acordo com os Descritores em Ciências da Saúde (DeCS) e Medical Subject Headings (MeSH) para cada item da estratégia. Dessa forma, foram utilizados para População (P): paciente AND cuidadores OR patient AND caregivers; Conceito (C): "dificuldade" OR “dificuldades" OR “difficulty” OR "difficulties"; Contexto (C): "cateterismo uretral intermitente" OR "cateterismo intermitente" OR "cateterismo urinário intermitente limpo" OR "intermittent catheterisation" OR "clean intermittent catheterization" OR "intermittent urethral catheterization" OR "urethral self catheterization".

Para a combinação dos descritores, foram considerados os termos booleanos AND e OR. Após a realização da busca, foram inclusos os estudos realizados nos idiomas português, inglês e espanhol, com abordagem quantitativa e qualitativa, estudos primários, revisões, metanálises e/ ou metassínteses, livros e roteiros, teses e dissertações, publicados em fontes indexadas ou na literatura cinzenta. As buscas foram executadas entre os meses de maio e junho de 2019, período durante o qual todas as publicações foram acessadas.

Para a seleção dos estudos, foi realizada a leitura criteriosa do título, resumo e palavras-chave, para análise de adequação aos critérios de inclusão e exclusão estabelecidos. Nas ocasiões em que o título, o resumo e os descritores não foram suficientes para definir a seleção, realizou-se a leitura do artigo na íntegra.

Para a extração dos dados, foi utilizado o instrumento estruturado pelos próprios pesquisadores conforme recomendações do JBI ${ }^{18}$. Para a apresentação dos resultados, os estudos foram numerados e denominados "estudo". $\mathrm{Na}$ análise crítica dos artigos selecionados, foi ainda realizada análise do delineamento dos estudos. 


\section{RESULTADOS}

A partir das buscas realizadas, foram identificados 790 estudos potenciais. Após a realização da leitura dos títulos e resumos, 95 estudos foram selecionados para leitura na íntegra, sendo 33 excluídos por estarem repetidos. Após análise na íntegra dos 62 estudos selecionados, 34 foram incluídos por responderem à questão da pesquisa. A descrição do processo de seleção e inclusão dos estudos encontra-se representada na Fig. 1.

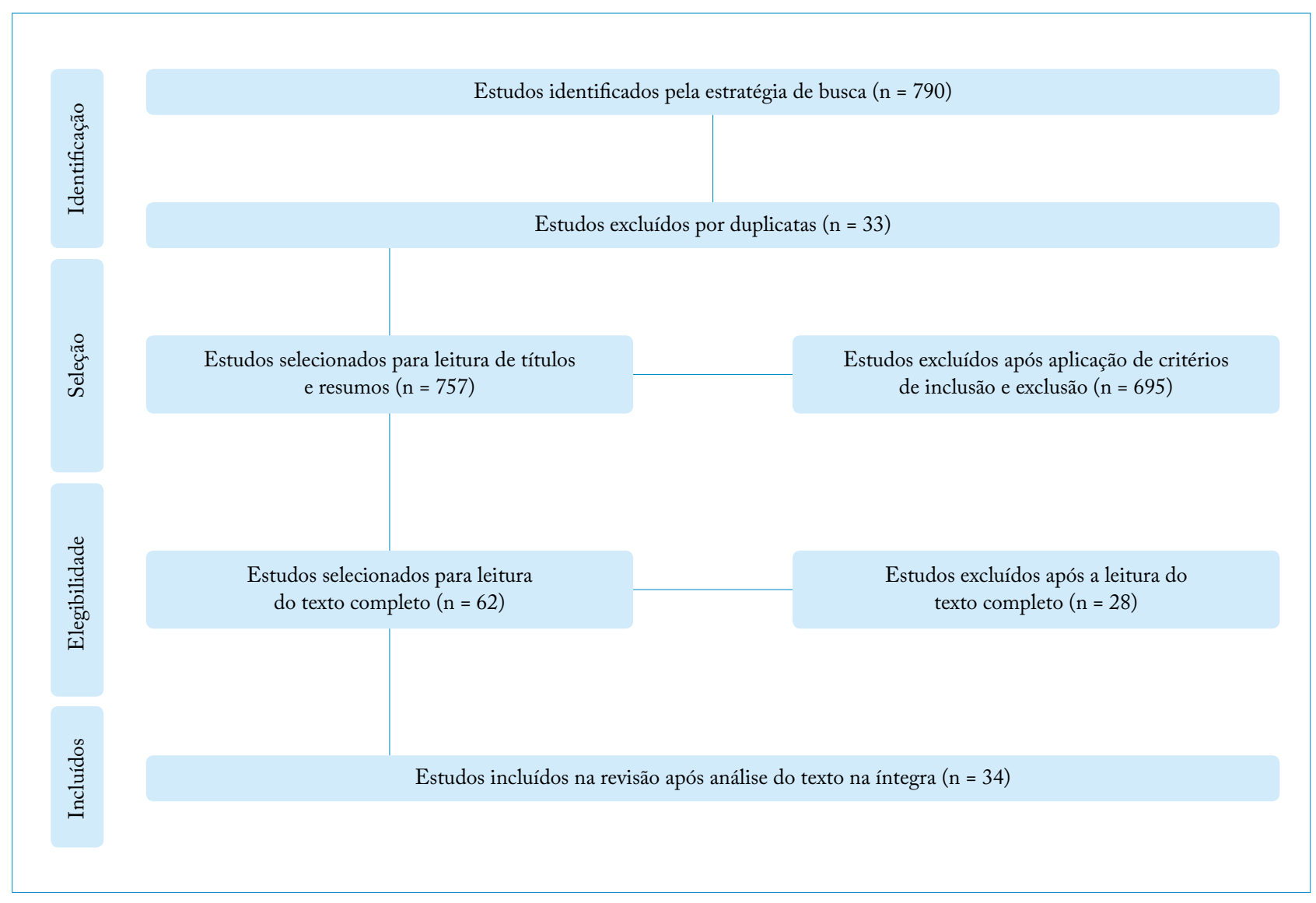

Figura 1. Fluxo do processo de seleção e inclusão dos estudos. Ribeirão Preto (SP), Brasil, 2019.

Os 34 estudos selecionados foram publicados em inglês (88,0\%), português $(9,0 \%)$ e espanhol (3,0\%), sendo a maioria (94,0\%) artigos científicos publicados na área da medicina $(64,7 \%)$ enfermagem $(26,4 \%)$ e parcerias entre medicina e enfermagem $(9,0 \%)$. Os estudos foram realizados no período de 1984 a 2019 e, dentre eles, 7 (20,6\%) foram publicados entre as décadas de 1980 e 90, 7 (20,6\%) entre os anos de 2000 a 2010 e $20(58,8 \%)$ foram publicados entre os anos de 2011 e 2019, o que pode apontar aumento de interesse no tema.

A Tabela 1 apresenta os estudos selecionados conforme $n$ amostral e média da idade em anos, tipo de participante, desenho metodológico, objetivos do estudo e principais dificuldades relatadas na realização do CIL.
Os estudos apontaram como dificuldades na realização do cateterismo intermitente limpo a dificuldade na inserção do cateter (64,7\%), a dor (35,0\%), o trauma uretral e o sangramento (26,4\%), as precárias instalações em banheiros públicos (26,4\%), as dificuldades físicas motoras e/ou visuais $(23,5 \%)$, a dificuldade no posicionamento corporal (23,5\%), o desconforto (20,5\%), o tempo gasto no preparo dos materiais e realização do procedimento $(15,0 \%)$, a falta de acesso aos insumos necessários (12,0\%), os espasmos musculares $(12,0 \%)$, a dificuldade de manuseio do cateter pré-lubrificado por ser escorregadio $(9,0 \%)$, o medo na realização do procedimento $(9,0 \%)$, a presença de fluxo menstrual no sexo feminino $(6,0 \%)$, a ausência do cuidador $(6,0 \%)$, a presença de fecaloma $(3,0 \%)$ e a obesidade $(3,0 \%)$. 
Tabela 1. Estudos inclusos conforme $n$ amostral e média de idade em anos, tipo de participante, desenho metodológico, objetivos do estudo e principais dificuldades relatadas na realização do cateterismo intermitente limpo. Ribeirão Preto (SP), Brasil, 2019.

\begin{tabular}{|c|c|c|c|c|c|}
\hline Estudo & $\begin{array}{l}\text { Amostra } \\
\text { (média } \\
\text { da idade } \\
\text { em anos) }\end{array}$ & Participante & $\begin{array}{l}\text { Desenho } \\
\text { metodológico }\end{array}$ & Objetivos do estudo & Principais dificuldades relatadas \\
\hline $1^{20}$ & $\begin{array}{l}65 \\
(67)\end{array}$ & Pacientes & $\begin{array}{l}\text { Quantitativo, } \\
\text { transversal, } \\
\text { descritivo }\end{array}$ & $\begin{array}{c}\text { Apresentar os dados de pacientes } \\
\text { com } 65 \text { anos ou mais em uso de } \\
\text { CIL. }\end{array}$ & $\begin{array}{l}\text { Dificuldade de inserção do cateter } \\
\text { por anomalia anatômica (cálculo } \\
\text { prostático); estenose uretral. }\end{array}$ \\
\hline $2^{21}$ & $\begin{array}{c}24 \\
(15,1)\end{array}$ & Pacientes & $\begin{array}{l}\text { Quantitativo, } \\
\text { transversal, } \\
\text { descritivo }\end{array}$ & $\begin{array}{c}\text { Relatar a experiência com } 24 \\
\text { crianças com espinha bífida que } \\
\text { possuem deficiência física e, em } \\
\text { alguns casos, mental. }\end{array}$ & $\begin{array}{l}\text { Dificuldade de coordenação } \\
\text { motora e ocular; curvatura da } \\
\text { coluna dificulta a realização do } \\
\text { CIL; menstruação; anormalidade } \\
\text { anatômica (na bexiga ou } \\
\text { coluna vertebral). }\end{array}$ \\
\hline $3^{22}$ & $\begin{array}{c}158 \\
(32,5)\end{array}$ & Pacientes & $\begin{array}{l}\text { Quantitativo, } \\
\text { transversal, } \\
\text { descritivo }\end{array}$ & $\begin{array}{l}\text { Avaliar se saliência do colo da } \\
\text { bexiga é uma variação normal ou } \\
\text { resultante de processo patológico } \\
\text { e seu significado funcional. }\end{array}$ & $\begin{array}{l}\text { Dificuldade na inserção do cateter } \\
\text { pela saliência; necessidade de } \\
\text { manipulação do cateter com } \\
\text { aplicação de força. }\end{array}$ \\
\hline $4^{23}$ & - & Artigos & $\begin{array}{l}\text { Artigo de } \\
\text { revisão }\end{array}$ & Descrever as práticas do CIL. & $\begin{array}{l}\text { Falta de destreza e/ou capacidade } \\
\text { mental; instalações inadequadas } \\
\text { nos banheiros públicos ou em } \\
\text { casa; sangramento uretral. }\end{array}$ \\
\hline $5^{24}$ & $\begin{array}{c}16 \\
(11)\end{array}$ & Pacientes & $\begin{array}{l}\text { Quantitativo, } \\
\text { prospectivo, } \\
\text { descritivo }\end{array}$ & $\begin{array}{c}\text { Avaliar a incidência e tipos de } \\
\text { complicações urológicas pós- } \\
\text { operatórias em pacientes com } \\
\text { mielomeningocele. }\end{array}$ & $\begin{array}{l}\text { Alteração da postura corporal; } \\
\text { imobilização gessada da } \\
\text { coluna vertebral. }\end{array}$ \\
\hline $6^{25}$ & $\begin{array}{c}90 \\
\text { (crianças) }\end{array}$ & Pacientes & $\begin{array}{l}\text { Quantitativo, } \\
\text { prospectivo, } \\
\text { descritivo }\end{array}$ & $\begin{array}{l}\text { Avaliar as sequelas urológicas } \\
\text { funcionais relacionadas a } \\
\text { disfunção do trato urinário } \\
\text { inferior. }\end{array}$ & $\begin{array}{l}\text { Causa angústia; sensibilidade } \\
\text { e dor; difícil cateterização após } \\
\text { construção de fístula retouretral. }\end{array}$ \\
\hline $7^{26}$ & $\begin{array}{c}18 \\
(8,9)\end{array}$ & Paciente & $\begin{array}{l}\text { Quantitativo, } \\
\text { prospectivo, } \\
\text { descritivo }\end{array}$ & $\begin{array}{l}\text { Atualizar os resultados e } \\
\text { descrever outros aspectos para } \\
\text { melhora da técnica cirúrgica de } \\
\text { neouretra (Pippi Salle). }\end{array}$ & $\begin{array}{l}\text { Dor durante o CIL; habilidades } \\
\text { motoras limitadas; necessidade de } \\
\text { mudar posição corporal. }\end{array}$ \\
\hline $8^{27}$ & $\begin{array}{l}39 \\
(45)\end{array}$ & Pacientes & $\begin{array}{l}\text { Quantitativo, } \\
\text { prospectivo, } \\
\text { descritivo }\end{array}$ & $\begin{array}{l}\text { Avaliar o uso de cateter } \\
\text { pré-lubrificado em homens } \\
\text { que fizeram uso de cateter } \\
\text { convencional por muito tempo. }\end{array}$ & $\begin{array}{l}\text { Dificuldade na introdução do } \\
\text { cateter por espasmos; dificuldade } \\
\text { de manipular cateter pré- } \\
\text { lubrificado por ser escorregadio; } \\
\text { sangramento e falso trajeto. }\end{array}$ \\
\hline $9^{28}$ & $\begin{array}{c}35 \\
(14,6)\end{array}$ & Pacientes & $\begin{array}{l}\text { Quantitativo, } \\
\text { prospectivo, } \\
\text { descritivo }\end{array}$ & $\begin{array}{l}\text { Verificar se o uso de cateter } \\
\text { hidrofílico garante maior } \\
\text { satisfação que os cateteres } \\
\text { habituais de PVC. }\end{array}$ & $\begin{array}{l}\text { Dificuldade na inserção do } \\
\text { cateter; desconforto na retirada } \\
\text { do cateter; tempo de preparo } \\
\text { dos materiais; dificuldade de } \\
\text { manipular cateter pré-lubrificado } \\
\text { por ser escorregadio. }\end{array}$ \\
\hline $10^{29}$ & $\begin{array}{c}62 \\
(39,6)\end{array}$ & Pacientes & $\begin{array}{l}\text { Quantitativo, } \\
\text { prospectivo, } \\
\text { randomizado, } \\
\text { multicêntrico }\end{array}$ & $\begin{array}{l}\text { Comparar o uso de cateter } \\
\text { lubrificado e cateter de PVC em } \\
\text { pacientes em uso do CIL. }\end{array}$ & $\begin{array}{l}\text { Dificuldade na inserção do cateter; } \\
\text { hematúria macroscópica. }\end{array}$ \\
\hline $11^{30}$ & $\begin{array}{c}1 \\
(84)\end{array}$ & Paciente & Relato de caso & $\begin{array}{l}\text { Descrever um caso incomum de } \\
\text { um fecaloma gigante na pelve. }\end{array}$ & $\begin{array}{l}\text { Dificuldade na inserção do cateter } \\
\text { por obstrução causada por } \\
\text { fecaloma gigante. }\end{array}$ \\
\hline
\end{tabular}


Tabela 1. Continuação...

\begin{tabular}{|c|c|c|c|c|c|}
\hline Estudo & $\begin{array}{l}\text { Amostra } \\
\text { (média } \\
\text { da idade } \\
\text { em anos) }\end{array}$ & Participante & $\begin{array}{l}\text { Desenho } \\
\text { metodológico }\end{array}$ & Objetivos do estudo & Principais dificuldades relatadas \\
\hline $12^{31}$ & $\begin{array}{c}20 \\
(12,3)\end{array}$ & $\begin{array}{l}\text { Pacientes e } \\
\text { cuidadores }\end{array}$ & $\begin{array}{l}\text { Quantitativo, } \\
\text { transversal, } \\
\text { descritivo }\end{array}$ & $\begin{array}{l}\text { Avaliar crianças com sensibilidade } \\
\text { genital em uso do CIL e avaliar } \\
\text { experiência com a técnica } \\
\text { e qualidade de vida desses } \\
\text { pacientes e seus pais. }\end{array}$ & $\begin{array}{c}\text { Apreensão; desconforto; falta de } \\
\text { vontade da criança em aprender } \\
\text { a técnica. }\end{array}$ \\
\hline $13^{32}$ & $\begin{array}{c}31 \\
(0,9)\end{array}$ & Pacientes & $\begin{array}{l}\text { Quantitativo, } \\
\text { prospectivo, } \\
\text { descritivo }\end{array}$ & & $\begin{array}{l}\text { Sangramento uretral; dificuldade } \\
\text { na inserção por pólipo uretral. }\end{array}$ \\
\hline $14^{33}$ & $\begin{array}{l}15 \\
(65)\end{array}$ & Pacientes & $\begin{array}{l}\text { Qualitativo } \\
\text { baseado } \\
\text { na teoria } \\
\text { fundamentada }\end{array}$ & $\begin{array}{c}\text { Descrever a experiência de } \\
\text { pessoas na realização do CIL e o } \\
\text { impacto em sua qualidade de vida. }\end{array}$ & $\begin{array}{l}\text { Dificuldade de encontrar } \\
\text { banheiros públicos com } \\
\text { instalações adequadas; } \\
\text { dificuldade na inserção do cateter } \\
\text { por espasmos musculares; } \\
\text { desconforto e dor (homens); } \\
\text { dificuldade de visualização do } \\
\text { meato uretral (mulheres); pouca } \\
\text { destreza manual. }\end{array}$ \\
\hline $15^{34}$ & $\begin{array}{c}8 \\
(45)\end{array}$ & Pacientes & Relato de caso & $\begin{array}{l}\text { Descrever dificuldades práticas na } \\
\text { realização do CIL. }\end{array}$ & $\begin{array}{l}\text { Falta de estrutura física em banheiros } \\
\text { públicos; falta de tempo; falta de } \\
\text { recursos humanos (cuidador); } \\
\text { dificuldade de visualização da } \\
\text { uretra; tipo de material utilizado } \\
\text { (cateter); resistência, sangramento } \\
\text { e falso trajeto. }\end{array}$ \\
\hline $16^{35}$ & - & Artigos & $\begin{array}{l}\text { Artigo de } \\
\text { Revisão }\end{array}$ & $\begin{array}{c}\text { Revisar o CIL em mulheres, } \\
\text { incluindo suas vantagens e } \\
\text { desvantagens. }\end{array}$ & $\begin{array}{l}\text { Dor e sangramento; dificuldade na } \\
\text { inserção e/ou remoção do cateter; } \\
\text { diminuição da acuidade visual; } \\
\text { destreza diminuída; mobilidade } \\
\text { reduzida; anormalidades } \\
\text { anatômicas; dificuldade na } \\
\text { localização do meato } \\
\text { uretral em mulheres; } \\
\text { ansiedade e desconforto. }\end{array}$ \\
\hline $17^{36}$ & $\begin{array}{c}1 \\
(75)\end{array}$ & Paciente & Relato de caso & $\begin{array}{l}\text { Relatar o caso de um paciente } \\
\text { com disfunção do detrusor e } \\
\text { pequena protusão da próstata. }\end{array}$ & $\begin{array}{c}\text { Dificuldade de inserção do cateter } \\
\text { por leve aumento da próstata. }\end{array}$ \\
\hline $18^{37}$ & $\begin{array}{c}1 \\
(13)\end{array}$ & Paciente & Relato de caso & $\begin{array}{l}\text { Descrever um caso de uma } \\
\text { técnica comum para labioplastia } \\
\text { redutora. }\end{array}$ & $\begin{array}{l}\text { Dificuldade de acesso à uretra e } \\
\text { inserção do cateter por hipertrofia } \\
\text { dos pequenos lábios. }\end{array}$ \\
\hline $19^{38}$ & $\begin{array}{l}44 \\
(56)\end{array}$ & Pacientes & $\begin{array}{l}\text { Quantitativo, } \\
\text { transversal, } \\
\text { descritivo }\end{array}$ & $\begin{array}{c}\text { Identificar barreiras autorrelatadas } \\
\text { na realização do CIL, descrever } \\
\text { complicações associadas, } \\
\text { examinar a aderência ao CIL e } \\
\text { avaliar qualidade de vida relatada. }\end{array}$ & $\begin{array}{l}\text { Falta de acesso a banheiros } \\
\text { públicos com adequada } \\
\text { infraestrutura; posicionamento } \\
\text { corporal para introdução do } \\
\text { cateter; falta de destreza } \\
\text { e espasticidade. }\end{array}$ \\
\hline $20^{3}$ & $\begin{array}{c}49 \\
(33,9)\end{array}$ & Pacientes & $\begin{array}{l}\text { Quantitativo, } \\
\text { transversal, } \\
\text { descritivo e } \\
\text { correlacional }\end{array}$ & $\begin{array}{l}\text { Investigar fatores que interferem } \\
\text { na continuidade do CIL e verificar } \\
\text { se há relação significante com o } \\
\text { suporte social. }\end{array}$ & $\begin{array}{c}\text { Falta de infraestrutura; limitação } \\
\text { financeira; dor e desconforto; } \\
\text { trauma uretral. }\end{array}$ \\
\hline
\end{tabular}


Tabela 1. Continuação...

\begin{tabular}{|c|c|c|c|c|c|}
\hline Estudo & $\begin{array}{l}\text { Amostra } \\
\text { (média } \\
\text { da idade } \\
\text { em anos) }\end{array}$ & Participante & $\begin{array}{c}\text { Desenho } \\
\text { metodológico }\end{array}$ & Objetivos do estudo & Principais dificuldades relatadas \\
\hline $21^{39}$ & $\begin{array}{c}7 \\
(10,1)\end{array}$ & Pacientes & $\begin{array}{l}\text { Qualitativo } \\
\text { desenvolvido } \\
\text { sobre o } \\
\text { método crítico } \\
\text { sensível }\end{array}$ & $\begin{array}{l}\text { Descrever as práticas de cuidados } \\
\text { no autocateterismo urinário limpo } \\
\text { realizado no domicílio e diversos } \\
\text { espaços pelos escolares e os } \\
\text { desafios enfrentados. }\end{array}$ & $\begin{array}{l}\text { Dificuldade de visualização } \\
\text { do meato uretral feminino } \\
\text { com necessidade de uso de } \\
\text { dispositivo para visualização do } \\
\text { meato urinário; dificuldade no } \\
\text { posicionamento para realização } \\
\text { da técnica; desconforto com } \\
\text { sondagem, dor e ardência; } \\
\text { falta de habilidade motora; } \\
\text { falta infraestrutura em } \\
\text { banheiros públicos. }\end{array}$ \\
\hline $22^{40}$ & $\begin{array}{l}174 \\
(11)\end{array}$ & $\begin{array}{l}\text { Pacientes e } \\
\text { cuidadores }\end{array}$ & $\begin{array}{l}\text { Qualitativo, } \\
\text { transversal, } \\
\text { descritivo }\end{array}$ & $\begin{array}{l}\text { Analisar a qualidade de vida } \\
\text { do binômio cuidador-criança e } \\
\text { identificar fatores envolvidos na } \\
\text { adesão ao programa de CIL. }\end{array}$ & $\begin{array}{l}\text { Dificuldade na aquisição de } \\
\text { materiais, local adequado para } \\
\text { realização do CIL, rotinas e } \\
\text { sobrecarga do procedimento } \\
\text { (cunho social); menstruação; } \\
\text { dor e desconforto durante a } \\
\text { realização do CIL. }\end{array}$ \\
\hline $23^{41}$ & $\begin{array}{c}70 \\
(56,1)\end{array}$ & Pacientes & $\begin{array}{l}\text { Artigo de } \\
\text { revisão } \\
\text { e estudo } \\
\text { metodológico }\end{array}$ & $\begin{array}{l}\text { Construir e validar um } \\
\text { questionário específico para } \\
\text { dificuldades no CIL. }\end{array}$ & $\begin{array}{l}\text { Espasmo e rigidez muscular; } \\
\text { sangramento local; alta } \\
\text { sensibilidade à dor; } \\
\text { complicação da doença. }\end{array}$ \\
\hline $24^{5}$ & $\begin{array}{c}200 \\
(14,5)\end{array}$ & $\begin{array}{l}\text { Pacientes e } \\
\text { cuidadores }\end{array}$ & $\begin{array}{l}\text { Quantitativo, } \\
\text { transversal, } \\
\text { descritivo }\end{array}$ & $\begin{array}{c}\text { Identificar e analisar os fatores } \\
\text { que podem contribuir para a } \\
\text { descontinuidade do CIL no Brasil e } \\
\text { Alemanha. }\end{array}$ & $\begin{array}{l}\text { Criança inquieta; dificuldade no } \\
\text { posicionamento e controle do } \\
\text { torso; resistência no esfíncter na } \\
\text { introdução do cateter; dificuldade } \\
\text { de visualização do meato uretral; } \\
\text { sensibilidade uretral e dor. }\end{array}$ \\
\hline $25^{42}$ & $\begin{array}{c}11 \\
(57)\end{array}$ & Pacientes & $\begin{array}{l}\text { Qualitativo } \\
\text { com análise } \\
\text { de conteúdo } \\
\text { temática }\end{array}$ & $\begin{array}{l}\text { Investigar barreiras e facilitadores } \\
\text { para pacientes lidando com CIL na } \\
\text { vida diária. }\end{array}$ & $\begin{array}{l}\text { Dificuldade de preparar os } \\
\text { materiais e realizar higiene; Falta } \\
\text { de acessibilidade e infraestrutura } \\
\text { em banheiros públicos; } \\
\text { Necessidade de mudar } \\
\text { posição corporal; }\end{array}$ \\
\hline $26^{43}$ & $\begin{array}{c}60 \\
(13)\end{array}$ & $\begin{array}{l}\text { Pacientes e } \\
\text { cuidadores }\end{array}$ & $\begin{array}{l}\text { Quantitativo, } \\
\text { prospectivo, } \\
\text { descritivo }\end{array}$ & $\begin{array}{l}\text { Pesquisar as atuais barreiras } \\
\text { relacionadas ao CIL em pacientes } \\
\text { coreanos com disrafismo espinhal. }\end{array}$ & $\begin{array}{l}\text { palta de local adequado na escola } \\
\text { gasto na realização da técnica; } \\
\text { indisponibilidade de alguém para } \\
\text { auxiliar no procedimento. }\end{array}$ \\
\hline $27^{44}$ & $\begin{array}{l}12 \\
(-)\end{array}$ & Cuidadores & $\begin{array}{l}\text { Qualitativo } \\
\text { com análise } \\
\text { de conteúdo } \\
\text { temática }\end{array}$ & $\begin{array}{l}\text { Compreender os sentimentos } \\
\text { vivenciados pelos familiares ao } \\
\text { cuidar da criança com bexiga } \\
\text { urinária neurogênica dependente } \\
\text { do CIL. }\end{array}$ & $\begin{array}{l}\text { Medo de não introduzir o cateter } \\
\text { no meato uretral; dificuldade de } \\
\text { visualização do meato uretral; } \\
\text { medo de causar dor à criança } \\
\text { durante o procedimento; negação } \\
\text { da nova realidade. }\end{array}$ \\
\hline $28^{45}$ & $\begin{array}{c}78 \\
(13,2)\end{array}$ & Pacientes & $\begin{array}{l}\text { Quantitativo, } \\
\text { prospectivo, } \\
\text { experimental, } \\
\text { randomizado }\end{array}$ & $\begin{array}{l}\text { Comparar cateter hidrofílico com } \\
\text { cateter padrão sem revestimento } \\
\text { em crianças com bexiga urinária } \\
\text { neurogênica. }\end{array}$ & $\begin{array}{l}\text { Dificuldade de manusear } \\
\text { cateter pré-lubrificado por ser } \\
\text { escorregadio; dificuldade na } \\
\text { inserção do cateter; dor uretral. }\end{array}$ \\
\hline
\end{tabular}


Tabela 1. Continuação...

\begin{tabular}{|c|c|c|c|c|c|}
\hline Estudo & $\begin{array}{l}\text { Amostra } \\
\text { (média } \\
\text { da idade } \\
\text { em anos) }\end{array}$ & Participante & $\begin{array}{c}\text { Desenho } \\
\text { metodológico }\end{array}$ & Objetivos do estudo & Principais dificuldades relatadas \\
\hline $29^{17}$ & $\begin{array}{c}55 \\
(31,7)\end{array}$ & $\begin{array}{l}\text { Pacientes e } \\
\text { cuidadores }\end{array}$ & $\begin{array}{l}\text { Quantitativo, } \\
\text { prospectivo, } \\
\text { quase- } \\
\text { experimental }\end{array}$ & $\begin{array}{c}\text { Avaliar as implicações da } \\
\text { simulação de baixa fidelidade } \\
\text { na competência de pacientes e } \\
\text { pardadores no uso de lubrificantes } \\
\text { para reação do CIL. }\end{array}$ & $\begin{array}{l}\text { Sangramento e trauma uretral; } \\
\text { drenagem negativa de urina; } \\
\text { resistência na introdução } \\
\text { do cateter. }\end{array}$ \\
\hline $30^{46}$ & $\begin{array}{c}202 \\
(73,7)\end{array}$ & Pacientes & $\begin{array}{l}\text { Quantitativo, } \\
\text { coorte } \\
\text { retrospectiva }\end{array}$ & $\begin{array}{l}\text { Explorar preditores de sucesso no } \\
\text { aprendizado do CIL em pacientes } \\
\text { acima de } 65 \text { anos. }\end{array}$ & $\begin{array}{l}\text { Incapacidade funcional e cognitiva; } \\
\text { obesidade; dificuldade de acesso } \\
\text { ao períneo e meato uretral; } \\
\text { dificuldade motora/destreza; } \\
\text { anormalidades anatômicas; } \\
\text { distúrbios de sensibilidade. }\end{array}$ \\
\hline $31^{47}$ & $\begin{array}{c}49 \\
(53)\end{array}$ & Pacientes & $\begin{array}{l}\text { Quantitativo, } \\
\text { prospectivo, } \\
\text { descritivo }\end{array}$ & $\begin{array}{c}\text { Avaliar a aderência à terapia } \\
\text { anticolinérgica e CIL em pacientes } \\
\text { com esclerose múltipla e } \\
\text { identificar os fatores associados à } \\
\text { aderência. }\end{array}$ & $\begin{array}{c}\text { Resistência (sensação de } \\
\text { bloqueio) na inserção do } \\
\text { cateter; necessidade de mudar } \\
\text { posicionamento do corpo; } \\
\text { necessidade de inserir os dedos } \\
\text { para realizar a técnica. }\end{array}$ \\
\hline $32^{48}$ & $\begin{array}{c}42 \\
(>65)\end{array}$ & Pacientes & $\begin{array}{l}\text { Quantitativo, } \\
\text { prospectivo, } \\
\text { descritivo }\end{array}$ & $\begin{array}{l}\text { Determinar a efetividade e } \\
\text { segurança do CIL em pacientes } \\
\text { com síndrome da cauda equina. }\end{array}$ & $\begin{array}{c}\text { Pacientes com mais de } 65 \text { anos } \\
\text { apresentaram maior dificuldade } \\
\text { na realização do CIL (inserção } \\
\text { do cateter). }\end{array}$ \\
\hline $33^{49}$ & $\begin{array}{c}97 \\
(37,7)\end{array}$ & Pacientes & $\begin{array}{l}\text { Quantitativo, } \\
\text { prospectivo, } \\
\text { descritivo }\end{array}$ & $\begin{array}{l}\text { Avaliar a qualidade de vida de } \\
\text { pacientes com estenose uretral } \\
\text { seguida de uretrotomia interna } \\
\text { sobão direta. }\end{array}$ & $\begin{array}{l}\text { Dificuldade na inserção do cateter; } \\
\text { sangramento uretral; dor na } \\
\text { realização do procedimento. }\end{array}$ \\
\hline $34^{50}$ & $\begin{array}{c}78 \\
(36,4)\end{array}$ & Pacientes & $\begin{array}{l}\text { Quantitativo, } \\
\text { transversal, } \\
\text { descritivo }\end{array}$ & $\begin{array}{l}\text { Identificar a taxa de continuidade } \\
\text { do CIL e as barreiras percebidas } \\
\text { para realização e continuidade do } \\
\text { procedimento. }\end{array}$ & $\begin{array}{l}\text { Falta de acessibilidade nos } \\
\text { banheiros; dificuldade de obter } \\
\text { os materiais necessários para } \\
\text { realização do procedimento. }\end{array}$ \\
\hline
\end{tabular}

\section{DISCUSSÃO}

O cateterismo urinário é a técnica de esvaziamento vesical considerada padrão ouro no tratamento das disfunções vesico-urinárias. É uma estratégia eficaz e segura que permite o esvaziamento vesical em intervalos regulares e previne as complicações da estase urinária. Além dos benefícios físicos, promove inclusão social, autoestima e independência e pode ser realizada tanto pelo paciente quanto pelo cuidador ${ }^{51,52}$.

Ao compreender que a estase urinária e a elevada pressão intravesical eram mais importantes do que o fator bacteriano na instalação das infecções urinárias, em 1972 foi introduzida a técnica do cateterismo intermitente limpo para substituir a técnica estéril, impraticável no cotidiano dos pacientes ${ }^{53}$. Desse modo, o CIL teve como objetivo diminuir os custos do procedimento estéril e promover aos seus usuários maior facilidade na execução da técnica, uma vez que tornou-se mais fácil e objetiva, assegurar sua execução, garantir sucesso na realização do procedimento, aumentar adesão ao tratamento e, assim, diminuir as complicações relacionadas à retenção urinária ${ }^{14,54}$.

Quando comparado ao cateterismo vesical de demora, o cateterismo intermitente limpo demonstra vantagem com relação à facilidade e à independência na sua utilização e menores taxas de infecções e complicações a curto e longo $\operatorname{prazo}^{14,54}$. 
Embora o CIL seja considerado uma técnica de fácil execução, ainda há dúvidas e incertezas na sua realização entre os profissionais e estudantes da área da saúde. Muitos são os mitos e rituais que permeiam o processo de higiene, antissepsia, escolha dos materiais que se mantêm na formação dos profissionais ${ }^{55,56}$.

Quando analisados os estudos desta revisão, a dificuldade na inserção do cateter foi a dificuldade mais relatada e pode estar relacionada a diversos fatores, sejam eles intrínsecos e/ou extrínsecos, como a anatomia do paciente, as manifestações da patologia de base, infraestrutura e materiais utilizados no procedimento. Entre os estudos analisados, foram citados como motivo de dificuldade na inserção do cateter a resistência na sua introdução $0^{5,17,34,47}$, os espasmos musculares ${ }^{27,33,38,41}$, as dificuldades de acesso à uretra ${ }^{5,39,46}$, o posicionamento $\operatorname{corporal}^{5,38,39}$, a manipulação do cateter pré-lubrificado ${ }^{27,28,45}$, a destreza ${ }^{35,46}$ e o aumento da próstata ${ }^{20,36}$.

A dor esteve presente em 12 estudos $3,5,25,26,33,35,39-41,45,46,49$ e geralmente está relacionada ao trauma uretral e ao sangramento, que também são mencionados como dificuldades $3,5,17,20,22,25,27-30,32-39,45-49$. A ocorrência dessas

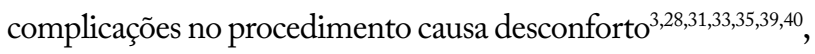
piora a experiência do indivíduo no uso do CIL, impacta negativamente na qualidade de vida e torna-os fatores que contribuem para a descontinuidade do tratamento ${ }^{5}$.

A dor é uma experiência sensorial e, também, emocional desagradável. Sua manifestação está associada a efetivos ou potenciais danos em tecidos. É um fenômeno multidimensional e compreende características físicosensoriais e fatores emocionais ${ }^{44,57}$.

O trauma uretral acontece pela inserção do cateter urinário mal lubrificado na uretra. Pela falta de lubrificação, pode ocorrer dificuldade na introdução e, com o aumento da força aplicada, ocorre atrito do cateter urinário contra a mucosa uretral com sua consequente lesão, causando dor e sangramento. Por criar uma porta de entrada para microrganismos ao romper a mucosa, o trauma uretral é considerado um dos principais fatores que levam ao desenvolvimento de infecção do trato urinário ${ }^{6}$. O trauma uretral pode estar relacionado aos insumos utilizados na realização do CIL e à falta de habilidade dos pacientes e cuidadores no procedimento ${ }^{6,58,59}$.

Além do trauma uretral, o sangramento e a resistência na introdução do cateter urinário também são apontados como fatores para diminuição da confiança na realização do CIL entre pacientes, profissionais e estudantes ${ }^{17,60,61}$.
A lidocaína em gel é o lubrificante mais utilizado na realidade brasileira para lubrificação da uretra, e é eficaz por diminuir a dor e a sensibilidade, promover certa dilatação uretral e facilitar a introdução do cateter urinário, diminuindo significativamente o risco de trauma uretral ${ }^{12,58}$. Entretanto diversos tipos de cateteres urinários estão disponíveis no mercado. Com mais tecnologia e com objetivo de oferecer maior comodidade e segurança aos usuários, o uso de cateteres lubrificados é recomendado. Quando comparado ao tradicional cateter de plástico (cloreto polivinil), o uso do cateter pré-lubrificado ou revestido está relacionado à redução de infecção do trato urinário e trauma uretral, à facilidade e ao conforto durante o cateterismo urinário ${ }^{9,10}$.

No entanto, apesar de demonstrar mais segurança e facilidade no seu uso, alguns pacientes encontram dificuldade na manipulação do cateter pré-lubrificado. Em três $(8,8 \%)$ estudos analisados, pacientes relataram dificuldade de manusear o cateter pré-lubrificado por ser escorregadio ${ }^{27,28,45}$. Por reduzir o atrito contra a mucosa uretral e diminuir a dor durante o procedimento, os cateteres urinários prélubrificados podem levar à maior aderência ao tratamento e seu uso está relacionado à melhor qualidade de vida dos seus usuários ${ }^{62}$.

Frequentemente, os pacientes encontram instalações inadequadas em banheiros públicos, desde estrutura física insipiente, até falta de higiene, falta de prateleiras para o preparo do material e pouca iluminação $\mathrm{o}^{3,23,33,34,38,39,42,43,50}$. Por saber das dificuldades enfrentadas nos espaços públicos com locais inapropriados para realização do CIL, alguns pacientes optam por limitar suas atividades para dentro de casa e acabam por ter restrições da vida social, onde a falta de infraestrutura induz isolamento ${ }^{3}$.

As dificuldades físicas, sejam motoras e visuais, muitas vezes estão relacionadas à patologia de base que levou à necessidade do cateterismo urinário para o esvaziamento vesical. Estudos mostram que os acometimentos neurológicos somam grande parte das doenças de base que levam a essa necessidade, seguidos por problemas prostáticos e câncer ${ }^{38,63,64}$.

A dificuldade motora e a falta de destreza manual contribuem para a presença de dificuldades e, geralmente, são resultados de função motora e sensibilidade prejudicadas em decorrência de doenças ou acometimentos neurológicos, como a esclerose múltipla, doença de Parkinson, mielomeningocele, acidente vascular encefálico e lesão medular ${ }^{21,23,26,33,35,38,39,46}$.

São diversas as condições clínicas que afetam o sistema nervoso central podendo resultar em alteração do tônus 
muscular e redução da atividade do sistema musculoesquelético, originando condições incapacitantes como a espasticidade, as quais podem diminuir a capacidade funcional do indivíduo ${ }^{65}$. O espasmo muscular é uma atividade motora involuntária, caracterizada por uma desordem motora, movimentos repetidos, aumento da resistência muscular, presença de movimentos exagerados de tendões, hiperreflexia e hipertonia devido à hiperexcitabilidade neuronal ${ }^{66}$.

Os estudos mencionam que os espasmos musculares, decorrentes das doenças de base, dificultam a realização do procedimento por afetar a mobilidade e a destreza até impedirem a introdução do cateter urinário quando acomete o esfíncter uretral ${ }^{27,33,38,41}$. A dificuldade visual mencionada também está relacionada aos acometimentos neurológicos e provocam dificuldades na realização do procedimento, desde o preparo dos materiais e higiene íntima até identificação da uretra e inserção do cateter urinário ${ }^{21,35}$.

Nesse sentido, nas avaliações realizadas durante o período inicial de reabilitação vesical, faz-se necessária a avaliação da capacidade funcional do paciente em desempenhar o cateterismo urinário por si mesmo, chamado autocateterismo, ou determinar a necessidade de um cuidador para desempenhar os cuidados de eliminação urinária no uso do $\mathrm{CIL}^{67}$.

Utilizada na avaliação das habilidades para a prática do autocateterismo intermitente limpo entre pacientes com distúrbios neurológicos, foi desenvolvido um teste denominado "pencil and paper test" ${ }^{68}$. O teste propõe gestos e simula manobras necessárias para realização do procedimento sozinho, analisando os recursos cognitivos e físicos indispensáveis paro o desenvolvimento da técnica. O teste é capaz de prever a capacidade da prática do procedimento sozinho ou indicar a necessidade do auxílio de um cuidador.

A ausência do cuidador foi citada como uma dificuldade para realização do CIL em alguns estudos desta busca, principalmente quando estão em ambientes fora de casa, como na escola ou no trabalho ${ }^{34,43}$.

Com relação às usuárias do CIL do sexo feminino, os estudos apontam a dificuldade de visualização do meato uretral.Tal dificuldade se dá pelas características anatômicas da genitália feminina que torna a visualização mais difícil do que nos homens $s^{5,33-35,37,39,44,46}$.

O meato uretral feminino pode estar mais distal ou mais profundo. Além disso, mulheres idosas geralmente não possuem claro conhecimento da anatomia genital. Para visualizar com mais facilidade o meato uretral, o uso do espelho é indicado ${ }^{5,46}$. Contudo, com o aperfeiçoamento das habilidades, as mulheres são capazes de deixar o espelho e identificar o meato uretral apenas através do toque ${ }^{53}$.

Uma situação também restrita às mulheres, o fluxo menstrual foi referido como um fator de dificuldade na execução da técnica. Contudo, após realização da higiene íntima, o procedimento pode ser realizado normalmente ${ }^{21,40}$.

O uso do CIL gera significativas mudanças nas atividades da vida dos pacientes que necessitam fazer seu uso ${ }^{62}$. Alguns pacientes consideram que o tempo gasto com preparo dos materiais e a realização do procedimento são fatores de dificuldade na realização e adesão ao CIL, por alterarem a rotina, tornarem-se um fardo e serem limitantes das atividades diárias. Para cuidadores de usuários do CIL, os sentimentos de sobrecarga e de limitação em sua própria vida também estão presentes $28,34,40,43$.

Durante o processo de reabilitação, os pacientes necessitam reorganizar seu contexto psicossocial, familiar, de rotinas e de trabalho. Essas mudanças também envolvem fatores financeiros e podem gerar custos relacionados aos materiais utilizados no procedimento ${ }^{69}$.

No Brasil, ainda não há política específica para garantir os materiais utilizados na realização do CIL. Contudo a população brasileira é assistida pelo Sistema Único de Saúde (SUS), que concebe saúde como direito fundamental do todo ser humano e atribui ao Estado o dever de proporcionar todas as condições fundamentais para seu pleno exercício, bem como garantir redução dos riscos de doenças e agravos. Nos princípios do SUS, também é prevista a assistência terapêutica integral. Assim, por lei, os usuários do CIL têm direito de receber todos os materiais necessários para a execução do procedimento ${ }^{62,70}$.

Entretanto os recursos disponibilizados aos usuários não são os que demonstram mais eficácia e segurança apontadas na literatura e, por vezes, não são suficientes para atender suas necessidades ${ }^{28,29,31}$. Ao enfrentar escassez de recursos na realização do CIL, alguns usuários necessitam racionar os insumos que possuem, sendo necessário diminuir a quantidade de lubrificante aplicado e reutilizar o mesmo cateter urinário por várias vezes ${ }^{12,71}$.

Um estudo realizado em uma perspectiva global aponta que essa realidade está relacionada ao desenvolvimento econômico da nação. Em países desenvolvidos, foi apontado que $83 \%$ dos participantes da pesquisa usuários do CIL nunca necessitaram reutilizar o cateter. Já nos países em desenvolvimento, apenas $27 \%$ dos participantes não faziam 
o reaproveitamento. Entre os participantes dos países em desenvolvimento, a média do número de infecções do trato urinário foi duas vezes maior em relação aos participantes dos países desenvolvidos ${ }^{71}$.

$\mathrm{Na}$ reutilização do cateter urinário, há na literatura relatos de diversas técnicas empregadas na higiene para seu reaproveitamento, tais como colocar o cateter urinário em água fervente, lavá-lo em água corrente, armazená-lo em solução com vinagre, detergente ou álcool a 70\% ou aquecê-lo no micro-ondas ${ }^{64,72}$.

Mesmo com o efeito antimicrobiano eficaz em alguns métodos de higiene para reuso do cateter urinário, estudos evidenciam que a reutilização está diretamente relacionada com o aumento da frequência das infecções do trato urinário ${ }^{71}$ Outro estudo relacionou a ausência de materiais adequados com o desenvolvimento de trauma uretral ${ }^{3}$.

Além de causar dificuldades na realização da técnica, a falta de acesso aos insumos adequados é citada por usuários do CIL como fator que causa descontinuidade no tratamento, influencia no conforto durante o procedimento e pode ser determinante para o sucesso ou insucesso da técnica e adesão do paciente ${ }^{38,62}$.

Por mais que seja considerada uma técnica de fácil execução, pacientes e seus cuidadores ainda enfrentam várias questões psicológicas, sociais e culturais, como o medo. O medo pode estar relacionado com o receio de inserir um cateter dentro do corpo e causar dor, dano ou lesionar o trato urinário. É um sentimento presente principalmente em cuidadores de crianças com sensibilidade preservada. Geralmente, é proveniente de sentimentos de incapacidade e também pode ser relativo a crenças culturais e orientações insuficientes. Por isso, a educação em saúde durante o processo de reabilitação tem papel fundamental na superação dos medos e dificuldades encontrados por pacientes usuários do CIL e seus cuidadores ${ }^{25,31,44}$.

Pacientes com bexiga urinária neurogênica comumente possuem alterações nas funções intestinais, devido à sua etiologia, podendo ser acometidos por intestino neurogênico $6^{9,73}$. O intestino neurogênico pode ser definido pela interrupção dos estímulos do sistema nervoso central, o que altera o processo de armazenamento e eliminação dos resíduos sólidos ${ }^{74,75}$. Dentre as complicações mais comuns, podem-se citar dor, constipação, incontinência fecal, impactação fecal, hemorroidas, fissuras anais, sangramento e prolapso retal $^{69,76}$.
Um estudo realizado em um centro de reabilitação apontou que aproximadamente $50 \%$ dos pacientes em uso do CIL faziam uso de medicações antiespasmódicas e anticolinérgicas ${ }^{64}$. Utilizados no tratamento farmacológico da bexiga hiperativa, os antiespasmódicos e anticolinérgicos atuam na musculatura lisa da bexiga e, assim, promovem aumento da capacidade vesical, diminuem espasmos do músculo detrusor, retardam o desejo inicial de miç̧ão e diminuem urgência, frequência e incontinência urinária ${ }^{77}$. Além disso, o uso de fármacos anticolinérgicos e antiespasmódicos pode inibir a secreção do ácido gástrico e deprimir a motilidade gastrointestinal, podendo causar um quadro de constipação ${ }^{78,79}$.

Pacientes com distensão retal podem ter a capacidade da bexiga diminuída em até $26 \%$ e, consequentemente, apresentam o primeiro desejo miccional e o desejo forte com menor volume de urina na bexiga quando comparado com o momento sem qualquer distensão retal ${ }^{79}$. Constipação e consequentemente impactação fecal são acometimentos multicausais mais comuns em idosos e se associam a dieta, desidratação, falta de atividade física,imobilização, medicações e doenças sistêmicas como esclerose múltipla, acidente vascular encefálico, demência e lesão medular. Em casos mais graves e incomuns, a impactação fecal pode obstruir completamente o trato urinário, bloqueando a uretra, os ureteres ou ambos ${ }^{80,81}$.

Esses fatos somados podem gerar perda de urina pela capacidade de armazenamento diminuída da bexiga e, raramente, podem causar dificuldade ou impedimento durante a inserção do cateter pela impactação fecal e distensão intestinal que leva à obstrução do trato urinário por compressão mecânica, conforme relatado no estudo ${ }^{11}$, que retrata o caso incomum de um fecaloma gigante ${ }^{30,79}$.

As complicações do intestino neurogênico podem limitar as atividades diárias, causando impactos psicossociais e econômicos, e dificultar o processo de reabilitação ${ }^{69}$. Pacientes insatisfeitos e com a capacidade de eliminação intestinal prejudicada têm uma percepção de qualidade de vida diminuída em relação aos que são satisfeitos, principalmente com relação à função social, trabalho, dor e desconforto ${ }^{76}$.

A obesidade surgiu ainda como dificuldade, visto que pode levar à incapacidade de acesso ao períneo devido ao acúmulo de gordura abdominal e excesso de pele que recai sobre o períneo. A diminuição da mobilidade relacionada a algumas doenças de base pode estar relacionada ao ganho de peso ${ }^{46}$. 


\section{CONCLUSÃO}

Os estudos analisados demostraram as dificuldades que os pacientes usuários do CIL e seus cuidadores enfrentam no dia a dia e estão associadas a fatores intrínsecos e extrínsecos, como destreza, manifestações da doença de base, infraestrutura, acesso aos materiais e complicações do uso do CIL. Também estão relacionadas a fatores institucionais, socioeconômicos e governamentais. Tais enfrentamentos diminuem a satisfação dos usuários, afetam a adesão aos programas de reabilitação vesical, podendo provocar danos no não tratamento e impactam negativamente na qualidade de vida dos pacientes e seus cuidadores. Nesse sentido, são necessários esforços da equipe multidisciplinar na educação em saúde para a adequada realização do CIL.

Embora esse estudo seja uma revisão de escopo e tenha cumprido seu papel no sentido de mapear os problemas encontrados pelos pacientes usuários de CIL, é possível observar entre os estudos encontrados que a maior parte trata-se de estudos descritivos, realizados com distintas amostras de pacientes e cuidadores, na maior parte adultos, mas de diferentes faixas etárias, o que não foi estratificado nesta revisão. Isso pode ser considerado um fator limitante deste trabalho e deve ser explorado em novas pesquisas que analisem, também, intervenções.

\section{CONTRIBUIÇÃO DOS AUTORES}

Conceitualização: Orlandin L e Mazzo A; Metodologia: Mazzo A e Nardi A; Investigação: Orlandin L; Mazzo A; Nardi A e Costa RRO; Redação - Primeira Versão: Orlandin L e Mazzo A; Redação - Revisão \& Edição: Orlandin L; Mazzo A; Nardi A e Costa RRO; Supervisão: Mazzo A e Nardi A.

\section{REFERÊNCIAS}

1. Di Benedetto P. Clean intermittent self-catheterization in neuro-urology. Eur J Phys Rehabil Med. 2011;47(4):651-9.

2. Vahr S, Cobussen-Boekhorst H, Eikenboom J, Geng V, Holroyd $\mathrm{S}$, Lester $\mathrm{M}$ et al. Catheterisation urethral intermittent in adults: Dilatation, urethral intermittent in adults. Evidencebased guidelines for best practice in urological health care. Netherlands: European Association of Urology Nurses; 2013.

3. Lopes MAL, Lima EDRP. Continuous use of intermittent bladder catheterization - can social support contribute? Rev Latino-Am Enfermagem. 2014;22(3):461-6. https://doi. org/10.1590/0104-1169.3268.2438

4. Bickhaus JA, Drobnis EZ, Critchlow WA, Occhino JA, Foster RT. The feasibility of clean intermittent self-catheterization teaching in an outpatient setting. Female Pelvic Med Reconstr Surg. 2015;21(4):220-4. https://doi.org/10.1097/ SPV.0000000000000155

5. Faleiros F, Pelosi G, Warschausky S, Tate D, Käppler C, Thomas E. Factors influencing the use of intermittent bladder catheterization by individuals with spina bifida in Brazil and Germany. Rehabil Nurs. 2018;43(1):46-51. https:// doi.org/10.1002/rnj.302

6. Newman DK, Willson MM. Review of intermittent catheterization and current best practices. Urol Nurs. 201;31(1):12-28. https://doi.org/10.7257/1053$816 \times .2012 .31 .1 .12$
7. Mazzo A, Bardivia CB, Jorge BM, Souza Júnior VD, Fumincelli $\mathrm{L}$, Mendes IAC. Cateterismo urinario permanente: práctica clínica. Enfermería Glob. 2015;14(2):50-77. https://doi. org/10.6018/eglobal.14.2.186251

8. Martins MS, Santos VLCG, Secoli SR, Mata SM, Nogueira DS, Souza DM. Estudo comparativo sobre dois tipos de cateteres para cateterismo intermitente limpo em crianças estomizadas. Rev Esc Enferm USP. 2009;43(4):865-71. https://doi.org/10.1590/S0080-62342009000400018

9. Sarica S, Akkoc $Y$, Karapolat $H$, Aktug $H$. Comparison of the use of conventional, hydrophilic and gel-lubricated catheters with regard to urethral micro trauma, urinary system infection, and patient satisfaction in patients with spinal cord injury: a randomized controlled study. Eur J Phys Rehabil Med. 2010;46(4):473-9.

10. Chartier-Kastler E, Denys P. Intermittent catheterization with hydrophilic catheters as a treatment of chronic neurogenic urinary retention. Neurourol Urodyn. 2011;30(1):21-31. https://doi.org/10.1002/nau.20929

11. Lamin E, Newman DK. Clean intermittent catheterization revisited. Int Urol Nephrol. 2016;48(6):931-9. https://doi. org/10.1007/s11255-016-1236-9

12. Mazzo A, Pecci GL, Fumincelli $L$, Neves RC, Santos RCR, Cassini MF, et al. Intermittent urethral catheterisation: the reality of the lubricants and catheters in the clinical practice 
of a Brazilian service. J Clin Nurs. 2016;25(21-22):3382-90. https://doi.org/10.1111/jocn.13466

13. Chan MF, Tan HY, Lian X, Ng LYG, Ang LLE, Lim LHL, et al. A randomized controlled study to compare the $2 \%$ lignocaine and aqueous lubricating gels for female urethral catheterization. Pain Pract. 2014;14(2):140-5. https://doi. org/10.1111/papr.12056

14. Ercole FF, Macieira TGR, Wenceslau LCC, Martins AR, Campos CC, Chianca TCM. Integrative review: evidences on the practice of intermittent/indwelling urinary catheterization. Rev Latino-Am Enfermagem. 2013;21(1):459-68. https://doi. org/10.1590/S0104-11692013000100023

15. Lima MB, Rebouças CBA, Castro RCMB, Cipriano MAB, Cardoso MVLML, Almeida PC. Construção e validação de vídeo educativo para orientação de pais de crianças em cateterismo intermitente limpo. Rev Esc Enferm USP. 2017;51:e03273. https://doi.org/10.1590/s1980$220 \times 2016005603273$

16. Roecker S, Budó MLD, Marcon SS. Trabalho educativo do enfermeiro na Estratégia Saúde da Família: dificuldades e perspectivas de mudanças. Rev Esc Enferm USP. 2012;46(3):641-9. https://doi.org/10.1590/S008062342012000300016

17. Orlandin L, Mazzo A, Meska MHG, Jorge BM, Cotta Filho CK, Fumincelli L. Low-fidelity simulation for patients and caregivers in the use of lubricants in clean intermittent catheterization. Int J Urol Nurs. 2018;12(1):9-15. https://doi. org/10.1111/ijun.12155

18. Peters MDJ, Godfrey C, Mclnerney P, Baldini SC, Khalil H, Parker D. Chapter 11: Scoping Reviews. In: Aromataris E, Munn Z, editors. Joanna Briggs Institute Reviewer's Manual. Adelaide: JBl; 2017.

19. Galvão CM, Sawada NO, Trevizan MA. Revisão sistemática: recurso que proporciona a incorporação das evidências na prática da enfermagem. Rev Latino-Am Enfermagem. 2004;12(3):549-56. https://doi.org/10.1590/S0104 11692004000300014

20. Bennett CJ, Diokno AC. Clean intermittent self-catheterization in the elderly. Urology. 1984;24(1):43-5. https://doi. org/10.1016/0090-4295(84)90386-8

21. Robinson RO, Cockram M, Strode M. Severe handicap in spina bifida: no bar to intermittent self catheterisation. Arch Dis Child. 1985;60(8):760-2. https://doi.org/10.1136/ adc.60.8.760

22. Perkash I, Friedland GW. Posterior ledge at the bladder neck: Crucial diagnostic role of ultrasonography. Urol Radiol. 1986;8(4):175-83. https://doi.org/10.1007/BF02924101

23. Neal DE, Lawson AL, Webb RJ, Robertson AS. Clean intermittent self-catheterization. Int Urogynecol J. 1993;4(1):50-5. https://doi.org/10.1007/BF00372814

24. Boemers TML, Soorani-Lunsing IJ, Jong TPVM, Pruijs HEH. Urological problems after surgical treatment of scoliosis in children with myelomeningocele. J Urol. 1996;155(3):1066-9. https://doi.org/10.1016/S0022-5347(01)66393-6
25. Boemers TML, Jong TPVM, van Gool JD, Bax KMA. Urologic problems in anorectal malformations. Part 2: Functional urologic sequelae. J Pediatr Surg. 1996;31(5):634-7. https:// doi.org/10.1016/S0022-3468(96)90663-6

26. Salle JLP, McLorie GA, Bägli DJ, Khoury AE. Modifications of and extended indications for the Pippi Salle procedure. World J Urol. 1998;16(4):279-84. https://doi.org/10.1007/ s003450050067

27. Wyndaele JJ, Ridder D, Everaert K, Heilporn A, CongardChassol B. Evaluation of the use of Urocath-Gel® catheters for intermittent self-catheterization by male patients using conventional catheters for a long time. Spinal Cord. 2000;38(2):97-9. https://doi.org/10.1038/sj.sc.3100958

28. Pereira PL, Urrutia MJM, Lobato L, Rivas S, Monereo EJ. Estudio comparativo del grado de satisfacción del paciente en cateterismo intermitente con el uso de las sondas lofric y las de cloruro de polivinilo. Actas Urol Esp. 2001;25(10):72530. https://doi.org/10.1016/S0210-4806(01)72708-8

29. Vapnek JM, Maynard FM, Kim J. A prospective randomized trial of the LoFric hydrophilic coated catheter versus conventional plastic catheter for clean intermittent catheterization. J Urol. 2003;169(3):994-8. https://doi. org/10.1097/01.ju.0000051160.72187.e9

30. Suzuki K, Sugaya Y, Tokue A. Giant stercoral stone and catheterization difficulty. Int J Urol. 2003;10(10):554-5. https://doi.org/10.1046/j.1442-2042.2003.00675.x

31. Alpert SA, Cheng EY, Zebold KF, Kaplan WE. Clean intermittent catheterization in genitally sensate children: patient experience and health related quality of life. J Urol. 2005;174(4):1616-9. https://doi.org/10.1097/01. ju.0000176620.02031.67

32. Lindehall B, Abrahamsson $\mathrm{K}$, Jodal U, Olsson I, Sillén U. Complications of clean intermittent catheterization in young females with myelomeningocele: 10 to 19 years of followup. J Urol. 2007;178(3):1053-5. https://doi.org/10.1016/j. juro.2007.05.071

33. Shaw C, Logan K, Webber I, Broome L, Samuel S. Effect of clean intermittent self-catheterization on quality of life: a qualitative study. J Adv Nurs. 2008;61(6):641-50. https://doi. org/10.1111/j.1365-2648.2007.04556.x

34. Vaidyanathan S, Soni BM, Singh G, Oo T, Hughes PL. Barriers to implementing intermittent catheterisation in spinal cord injury patients in Northwest Regional Spinal Injuries Centre, Southport, U.K. Sci World J. 2011;5(11):77-85.

35. Rantell A. Intermittent self-catheterisation in women. Nurs Stand. 2012;26(42):61-8. https://doi.org/10.7748/ ns2012.06.26.42.61.c9164

36. Spernat $\mathrm{D}$, Woo $\mathrm{HH}$. Mini-photoselective vaporization of the prostate for difficult intermittent self-catheterization. Koren J Urol. 2012;53(9):654-6. https://doi.org/10.4111/ kju.2012.53.9.654

37. Wu JA, Braschi EJ, Gulminello PL, Comiter CV. Labioplasty for hypertrophic labia minora contributing to recurrent urinary tract infections. Female Pelvic Med Reconstr 
Surg. 2013;19(2):121-3. https://doi.org/10.1097/ SPV.0b013e31827de473

38. Bolinger R, Engberg S. Barriers, complications, adherence, and self-reported quality of life for people using clean intermittent catheterization. J Wound Ostomy Continence Nurs. 2013;40(1):83-9. https://doi.org/10.1097/ WON.0b013e3182750117

39. Souza SM. Práticas de cuidado e desafios do autocateterismo intermitente limpo: as vozes dos escolares [dissertação]. [Rio de Janeiro]: Universidade do Estado do Rio de Janeiro; 2015.

40. Alencar VP. Cateterismo vesical intermitente limpo em crianças e adolescentes: análise da qualidade de vida do binômio cuidador-criança e dos fatores envolvidos [tese]. [São Paulo]: Universidade de São Paulo; 2016.

41. Guinet-Lacoste A, Jousse M, Tan E, Caillebot M, Breton $F$, Amarenco $G$. Intermittent catheterization difficulty questionnaire (ICDQ): A new tool for the evaluation of patient difficulties with clean intermittent selfcatheterization. Neurourol Urodyn. 2016;35(1):85-9. https:// doi.org/10.1002/nau.22686

42. Cobussen-Boekhorst H, Hermeling E, Heesakkers J, van Gaal B. Patients' experience with intermittent catheterisation in everyday life. J Clin Nurs. 2016;25(9-10):1253-61. https://doi. org/10.1111/jocn.13146

43. Lim S-W, Lee H-E, Davis M, Park K. Perceived barriers and difficulties of intermittent catheterization: In Korean patients with spinal dysraphism and their parents. Neurourol Urodyn. 2016;35(3):395-9. https://doi.org/10.1002/nau.22716

44. Antonio S, Pacheco STA, Gomes MPF, Bossa PMA, Castro FM, Pereira MCR. Tradução dos sentimentos de familiares no cuidar da criança dependente do cateterismo intermitente limpo. Rev Enferm UERJ. 2016;24(4):e19990. https://doi. org/10.12957/reuerj.2016.19990

45. DeFoor W, Reddy P, Reed M, VanderBrink B, Jackson E, Zhang $B$, et al. Results of a prospective randomized control trial comparing hydrophilic to uncoated catheters in children with neurogenic bladder. J Pediatr Urol. 2017;13(4):373.E15. https://doi.org/10.1016/j.jpurol.2017.06.003

46. Hentzen C, Haddad R, Ismael SS, Peyronnet B, Gamé X, Denys $P$, et al. Intermittent self-catheterization in older adults: predictors of success for technique learning. Int Neurourol J. 2018;22(1):65-71. https://doi.org/10.5213/ inj.1835008.504

47. Montovasseli D, Chesnel C, Charlanes A, Menoux $D$, Charoenwong F, Le Breton $F$, et al. Adherence to anticholinergic therapy and clean intermittent selfcatheterization in patients with multiple sclerosis. Int Neurourol J. 2018;22(2):133-41. https://doi.org/10.5213/ inj.1836054.027

48. Sharif MM, Kazmi SAM, Mukhtar M, Khan AZ. Role of intermittent self catheterization after cauda equina syndrome surgery. JRMC. 2018;22(1):54-7.
49. Jhanwar A, Sokhal AK, Singh K, Sankhwar S, Saini DK. Assessment of quality of life in patients of urethral stricture on clean intermittent catheterization following direct vision internal urethrotomy. Urol Ann. 2018;10(4):395-9. https:// doi.org/10.4103/UA.UA_34_17

50. Baniya M, Groves CC, Bhattarai M. Intermittent catheterisation practice of people with spinal cord injury in five districts of Nepal. Australian and New Zealand Continence Journal. 2019;25(1):10-5.

51. Woodward S, Rew M. Patients' quality of life and clean intermittent self-catheterization. Br J Nurs. 2003;12(18):106674. https://doi.org/10.12968/bjon.2003.12.18.11782

52. Assis GM, Faro ACM. Autocateterismo vesical intermitente na lesão medular. Rev Esc Enferm USP. 2011;45(1):289-93. https://doi.org/10.1590/S0080-62342011000100041

53. Lapides J, Diokno AC, Silber SJ, Lowe BS. Clean, intermittent self-catheterization in the treatment of urinary tract disease. J Urol. 1972;107(3):458-61. https://doi.org/10.1016/500225347(17)61055-3

54. Zambon JP, Cintra CC, Bezerra CA, Bicudo MC, Wroclawsk ER. What is the best choice for chronic urinary retention: indwelling catheter or clean intermittent catheterization? Einstein. 2009;7(4):520-4.

55. Mazzo A, Godoy S, Alves LM, Mendes IAC, Trevizan MA, Rangel EML. Cateterismo urinário: facilidades e dificuldades relacionadas à sua padronização. Texto Contexto Enferm. 2011;20(2):333-9. https://doi.org/10.1590/S010407072011000200016

56. Dourado DX, Valença MP. Avaliação do conhecimento dos enfermeiros sobre o cateterismo intermitente limpo em um hospital escola da cidade do Recife. ESTIMA, Braz J Enterostomal Ther. 2013;11(1):2.

57. Kopf A, Patel NB. Guide to pain management in low-resource settings. Washington: IASP; 2010.

58. Bardsley A. Use of lubricant gels in urinary catheterisation. Nurs Stand. 2005;20(8):41-6. https://doi.org/10.7748/ ns2005.11.20.8.41.c3992

59. Kashefi C, Messer K, Barden R, Sexton C, Parsons JK. Incidence and prevention of iatrogenic urethral injuries. J Urol. 2008;179(6):2254-8. https://doi.org/10.1016/j. juro.2008.01.108

60. Mazzo A, Martins JCA, Jorge BM, Baptista RCN, Almeida RGS, Henriques FMD, et al. Validation of the selfconfidence scale of nursing care in urinary retention. Rev Latino-Am Enfermagem. 2015;23(5):814-20. https://doi. org/10.1590/0104-1169.0256.2619

61. Silva DR, Mazzo A, Jorge BM, Souza Júnior VD, Fumincelli L, Almeida RGS. Intermittent urinary catheterization: the impact of training on a low-fidelity simulator on the self-confidence of patients and caregivers. Rehabil Nurs. 2017;42(2):97-103. https://doi.org/10.1002/rnj.226

62. Fumincelli L, Mazzo A, Martins JCA, Henriques FMD, Orlandin L. Quality of life of patients using intermittent urinary 
catheterization. Rev Latino-Am Enfermagem. 2017;25:e2906. https://doi.org/10.1590/1518-8345.1816.2906

63. Silva MB, Oliveira LFT, Ferreira ML, Santos LCR. Cateterismo Vesical Intermitente: Análise Epidemiológica. ESTIMA, Braz J Enterostomal Ther. 2005;3(1).

64. Mazzo A, Souza Júnior VD, Jorge BM, Fumincelli L, Trevizan MA, Ventura CAA, et al. Qualidade e segurança do cuidado de enfermagem ao paciente usuário de cateterismo urinário intermitente. Esc Anna Nery. 2017;21(2):e20170045.

65. Pavan K, Marangoni BEM, Shimizu WAL, Mattos SE, Ferrari PP, Martins SRG, et al. Validation of the Santa Casa evaluation of spasticity scale. Arq Neuro-Psiquiatr. 2010;68(1):56-61. https://doi.org/10.1590/S0004-282X2010000100013

66. Bolaños-Jiménez R, Arizmendi-Vargas J, Calderón-Álvarez TJL, Carrillo-Ruiz JD, Rivera-Silva G, Jiménez-Ponce $F$. Espasticidad, conceptos fisiológicos y fisiopatológicos aplicados a la clínica. Rev Mex Neuroci. 2011;12(3):141-8.

67. Seth JH, Haslam C, Panicker JN. Ensuring patient adherence to clean intermittent self-catheterization. Patient Prefer Adherence. 2014;8:191-8. https://doi.org/10.2147/PPA.S49060

68. Amarenco $G$, Guinet $A$, Jousse $M$, Verollet $D$, Ismael SS. Pencil and paper test: A new tool to predict the ability of neurological patients to practice clean intermittent selfcatheterization. J Urol. 2011;185(2):578-82. https://doi. org/10.1016/j.juro.2010.09.106

69. Santos RCR, Fumincelli L, Nassif A, Souza Júnior VD, Jorge BM, Mazzo A. Paciente com bexiga neurogênica: cateterismo urinário intermitente e cuidados intestinais. Rev Enferm UFPE online. 2015;9(Supl. 7):8953-60.

70. Brasil. Lei nº. 8.080, de 19 de setembro de 1990. Dispõe sobre as condições para a promoção, proteção e recuperação da saúde, a organização e o funcionamento dos serviços correspondentes e dá outras providências. Diário Oficial da União 19 set 1990. [citado em 7 Set 2019]. Disponível em: http://www.planalto.gov.br/ccivil_03/leis/8080.htm

71. Krassioukov A, Cragg JJ, West C, Voss C, Krassioukov-Enns D. The good, the bad and the ugly of catheterization practices among elite athletes with spinal cord injury: a global perspective. Spinal Cord. 2015;53(1):78-82. https://doi. org/10.1038/sc.2014.208
72. Bogaert GA, Goeman L, Ridder D, Wevers M, Ivens J, Schuermans A. The physical and antimicrobial effects of microwave heating and alcohol immersion on catheters that are reused for clean intermittent catheterisation. Eur Urol. 2004;46(5):641-6. https://doi.org/10.1016/j. eururo.2004.06.016

73. Lie HR, Lagergren J, Rasmussen F, Lagerkvist B, Hagelsteen J, Börjeson M-C, et al. Bowel and bladder control of children with myelomeningocele: a Nordic study. Dev Med Child Neurol. 1991;33(12):1053-61. https://doi. org/10.1111/j.1469-8749.1991.tb14827.x

74. Bruni DS, Strazzieri KC, Gumieiro MN, Giovanazzi R, Sá VG, Faro ACM. Aspectos fisiopatológicos e assistenciais de enfermagem na reabilitação da pessoa com lesão medular. Rev Esc Enferm USP. 2004;38(1):71-9. https://doi. org/10.1590/S0080-62342004000100009

75. Furlan MLS, Caliri MHL, Defino HL. Intestino neurogênico: Guia prático para pessoas com lesão medular - Parte I. Coluna/Columna. 2005;4(3):113-68.

76. Pardee C, Bricker D, Rundquist J, MacRae C, Tebben C. Characteristics of neurogenic bowel in spinal cord injury and perceived quality of life. Rehabil Nurs. 2012;37(3):12835. https://doi.org/10.1002/RNJ.00024

77. Ávila LC editor. AME - Dicionário de administração de medicamentos na enfermagem. São Paulo: Epub; 2013.

78. Potter PA, Perry AG. Fundamentos de Enfermagem. Rio de Janeiro: Elsevier; 2009.

79. Panayi DC, Khullar V, Digesu GA, Spiteri M, Hendricken C, Fernando R. Rectal distension: The effect on bladder function. Neurourol Urodyn. 2011;30(3):344-7. https://doi. org/10.1002/nau.20944

80. Knobel B, Rosman P, Gewurtz G. Bilateral hydronephrosis due to fecaloma in an elderly woman. J Clin Gastroenterol. 2000;30(3):311-3. https://doi.org/10.1097/00004836200004000-00022

81. Yuan R, Zhao GG, Papez S, Cleary JP, Heliotis A. Urethral obstruction and bilateral ureteral hydronephroses secondary to fecal impaction. J Clin Gastroenterol. 2000;30(3):314-6. https://doi.org/10.1097/00004836-200004000-00023 